MATEC Web of Conferences 37, 01033 (2015)

DOI: $10.1051 /$ matecconf $/ 20153701033$

(C) Owned by the authors, published by EDP Sciences, 2015

\title{
NONISOTHERMAL DESORPTION OF THE LIBR AQUEOUS SALT SOLUTION IN MINICHANNELS
}

\author{
S.Y. Misyura ${ }^{1 \mathrm{a}}$, V.S.Morozov ${ }^{1}$ \\ ${ }^{1}$ Institute of Thermophysics Siberian Branch, Russian Academy of Sciences, Lavrentiev Ave. 1, \\ Novosibirsk, 630090, Russia
}

\begin{abstract}
This work is devoted the research for two (three)-phase flows of $\mathrm{LiBr}$ water solution in minichannels with different heat flux and wall thicknesses. Six flow patterns have been observed: a bubble flow, plug flow, laminar and oscillating laminar flow, mist flow, and flow locking. The physical solution properties and the equilibrium conditions change in time. The desorption rate depends not only on the heat flow and speed ratio of vapor to liquid, but also on the total area of the interface (liquid-vapor). The third phase (solid crystal hydrates) are formed under high heat fluxes and in the presence of boiling crisis. A variation in the wall thickness leads to a change in the desorption mode. With increasing wall thickness the boiling crisis is realized at higher heat fluxes.
\end{abstract}

\section{Introduction}

Heat and mass transfer and capillary hydrodynamics in minichannels are being increasingly used in practice [1]. Depending on the tube transverse size, the classification is done by the ratio of pipe diameter $D$ or channel height $H$ to capillary constant $L \sigma$ [2]: 1) convective channels (macrochannels), where inertia forces prevail; 2) gravity capillary channels (minichannels), where gravity forces prevail over capillary ones; 3 ) capillary-gravity minichannels, where capillary forces prevail over gravity forces; 4) capillary microchannels, where the gravity forces can be neglected. The challenge of mapping modes for iso-thermal flows in minichannels is basically solved. Maps modes for non-isothermal flows is facing great difficulties. To date, the task of drawing diagram of brines flow patterns has not been solved. One and the same criterion for the different modes can lead to contradictory conclusions. There is a change of the solution physical properties and the equilibrium conditions in time. The evaporation of droplets in the flow of the oncoming air investigated in [3]. The aqueous $\mathrm{LiBr}$ solution behavior discussed in [4-7]. Liquid evaporation was investigated in [8-18]. The explosive with a mixture of liquid nitrogen jet and water and fine droplets evaporation is represented in [19-20]. Three-phase flows of $\mathrm{LiBr}$ water solution in minichannels with different heat flux and wall thicknesses have been studied in this work.

\section{Experimental data}

In the horizontal cylindrical channel (the quartz glass thickness was 0.5-6 $\mathrm{mm}$ in diameter, $\mathrm{p}=1 \mathrm{bar}$ ) was fed an aqueous solution of lithium bromide. The flow rate was constant. The heating of the outer

${ }^{a}$ Corresponding author: misyura@itp.nsc.ru

This is an Open Access article distributed under the terms of the Creative Commons Attribution License 4.0, which permits unrestricted use, distribution, and reproduction in any medium, provided the original work is properly cited. 
glass wall produced by a constant heat flux. $\mathrm{LiBr}$ aqueous solution with a salt concentration of about $48 \%$ was fed to the channel. Two-phase mixture (steam-water) was created as a result of heating the wall. The wall temperature increases from $95{ }^{\circ} \mathrm{C}$ (at the beginning of the channel) to $160{ }^{\circ} \mathrm{C}$ (at the end of the channel). The following desorption modes have been found with increasing heat flux on the wall (Fig. 1): 1) the bubble mode; 2) the plug mode; 3) the laminated mode; 4) the oscillating laminated mode; 5) the emulsion mode; 6) the flow choking mode with crystalline hydrate. The maximum efficiency of a non-isothermal high-temperature desorption was realized for the emulsion mode. Heat and mass transfer efficiency is determined by desorption of fine droplets in the core stream for emulsion regime and due to impact of droplets on the wall surface. To evaluate the intensity of the phase transition (liquid - (steam + salt)) we introduced parameter - the desorption efficiency $\left(\Delta C=C_{2}-C_{l}\right.$, where $C_{l}$ is the mass concentration of the salt at the input of channel, $C_{2}$ - the mass concentration at the exit of the channel). Desorption efficiency has allowed to compare different flow regimes. The higher $\Delta C$, the higher the efficiency of desorption. The efficiency is a function of $\Delta \mathrm{C}$ and the total liquid-vapor interface area $(S)$. During emulsion desorption mode (high overheating) the role of accounting in the wall thickness increases substantially. Experiments for quartz tubes with thickness of $\delta=0.5-6 \mathrm{~mm}$ were carried out.

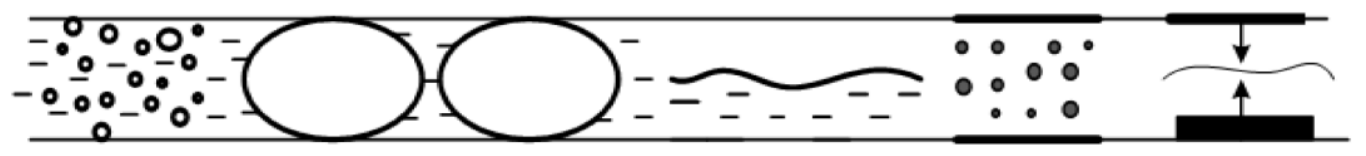

(1)

(2)

$(3,4)$

(5)

(6)

Figure. 1. A scheme of flow patterns for water-salt solution.

The data for $\Delta \mathrm{C}$ are shown in Table. Under the identical liquid flow rates and the heat fluxes a variation in the wall thickness leads to a change in the desorption mode. The emulsion mode with the wall thickness of $\delta=3 \mathrm{~mm}$ was not observed due to the strong cooling of the inner glass surface.

Table 1. The effect of the wall thickness on desorption.

\begin{tabular}{|c|c|c|c|c|}
\hline The wall thickness $\delta$, MM & $0.5-1$ & $1-2$ & $3-4$ & $5-6$ \\
\hline The flow regime & $\begin{array}{c}\text { choking } \\
\text { mode (6) }\end{array}$ & Emulsion (5) & $\begin{array}{c}\text { the oscillating laminated } \\
\text { mode (4) }\end{array}$ & Plug (2) \\
\hline $\begin{array}{c}\text { The efficiency of } \\
\text { desorption } \Delta C, \%\end{array}$ & - & 11,5 & $2-3.5$ & $1.5-2$ \\
\hline
\end{tabular}

\section{Conclusion}

The following desorption modes have been found: 1) the bubble mode; 2) the plug mode; 3 ) the laminated mode; 4) the oscillating laminated mode; 5) the emulsion mode; 6) the flow choking mode with crystalline hydrate. The maximum efficiency of a non-isothermal and hightemperature desorption was realized for the emulsion mode. At high minichannel overheating the effect of the wall properties (a thickness, a type of a material) can lead to a change in the desorption mode and intensity of heat and mass transfer.

This work was supported by grants of Russian Science Foundation (Project № 15-19-10025).

\section{References}

1. O.A. Kabov, V.V. Kuznetsov and J-C. Legros, Heat transfer and film dynamic in shear-driven liquid film cooling system of microelectronic equipment, (Proc. Second Int. Conf. on Microchannel and Minichannels, USA, Rochester, ASME, 2004) 
2. E.A. Chinnov and O.A. Kabov, Teplof. Vys. Temp., 44 (5), 777 (2006)

3. V.I. Terekhov, N.E. Shishkin, Technical Physics Letters, 38 (1), 51 (2012)

4. V.E. Nakoryakov, S.Ya. Misyura, S.L. Elistratov, R.A. Dekhtyar, J. Engineering Thermophysics, 23 (4), 25 (2014).

5. V.E. Nakoryakov, N.S. Bufetov, R.A. Dekhtyar, J. Appl. Mech. \& Tech. Phys., 45 (2), 276 (2004)

6. V.E. Nakoryakov, N.S. Bufetov, N.I. Grigoryeva, R.A. Dekhtyar, Journal of Applied Mechanics and Technical Physics, 44 (2), 101 (2003)

7. V.E. Nakoryakov, S.Y. Misyura, S.L. Elistratov, J. Engineering Thermophysics, 20 (4), 1 (2011)

8. A.N. Pavlenko, V.E. Zhukov, N.I. Pecherkin, V.Yu. Chekhovich, O.A. Volodin, A. Shilkin, C. Grossmann, AIChE J., 60 (2), 690 (2014)

9. A.N. Pavlenko, A.A. Tairov, V.E. Zhukov, A.A. Levin, A.N. Tsoi, J. Engineering Thermophysics, 20 (4), 1 (2011)

10. M.V. Bartashevich, O.A. Kabov, V.V. Kuznetsov, Fluid Dynamics, 45 (6), 924 (2010)

11. D.V. Feoktistov, G.V. Kuznetsov, E.G. Orlova, EPJ Web of Conferences, 76, 012039 (2014)

12. D.V. Feoktistov, K.A. Batischeva, E.G. Orlova, MATEC Web of Conferences, 19, 01001 (2014)

13. D.V. Feoktistov, I.A. Afanasyev, E.G. Orlova, EPJ Web of Conferences 82, 01054 (2015)

14. V.E. Nakoryakov, S.Y. Misyura, Doklady Physics, 59 (10), 441 (2014)

15. S.Ya. Misyura, Int. J. Thermal Sci., 92, 34 (2015)

16. S.Ya. Misyura, Int. J. Heat Mass Transfer, 71, 197 (2014)

17. D.V. Feoktistov, E.G. Orlova, G.V. Kuznetsov, EPJ Web of Conferences 82, 01053 (2015)

18. S.Y. Misyura, Wall effect on heat transfer crisis, Exp. Thermal Fluid Sci, Doi:http: //dx.doi.org/10.1016/j.expthermflusci.2015.10.002, (2015)

19. V.E. Nakoryakov, A.N. Tsoi, I.V. Mezentsev, A.V. Meleshkin, J. Engineering Thermophysics, 23 (1), 1 (2014)

20. V.E. Nakoryakov, A.N. Tsoi, I.V. Mezentsev, A.V. Meleshkin, Thermophys. and Aeromech, 21 (3), 279 (2014) 